\title{
Sustitución constitucional y objeción democrática: una tensión aparente The constitutional replacement and the democratic objection: an apparent tension
}

\author{
Fernando Alonso Tovar Uricoechea 1 \\ Fundación Universitaria Juan de Castellanos - Colombia \\ fertovaru@gmail.com
}

Recibido / received:18/10/2016

Aceptado / accepted:03/02/2017

DOI: https://doi.org/10.20318/eunomia.2017.3642

\begin{abstract}
Resumen
La teoría de la sustitución constitucional es una construcción jurisprudencial a través de la cual se sustenta el control judicial de las reformas constitucionales en Colombia tomando como base los vicios de competencia. En este trabajo se observará una aproximación teórica en relación con este concepto y, además, se explicará de manera elemental el problema de la llamada "objeción democrática" al control de constitucionalidad de las leyes (entiéndase incluidas las reformas constitucionales) para finalmente formular una contestación tomando en cuenta la teoría de la sustitución constitucional.
\end{abstract}

\section{Palabras clave}

Sustitución constitucional, mutación constitucional, objeción democrática, test de sustitución, poder constituyente, poder de reforma.

\begin{abstract}
The constitutional replacement theory is a jurisprudence construction that supports the judicial review of constitutional amendments in Colombia, taking on account the main idea that the power to amend the Constitution is different from the power to replace it. In this paper I will make a theorical approach to this concept. Besides, I will explain in an elemental way the problem of the democratic objection to the constitutional control of the law (even the amendments), and finally I will answer to that objection having on account the constitutional replacement theory.
\end{abstract}

\section{Keywords}

Constitutional replacement, constitutional mutation, democratic objection, replacement test, constituent power, reform power.

\footnotetext{
1 Abogado por la Universidad Santo Tomás de Colombia, sede Tunja, Máster en Derecho Constitucional por la Universidad Internacional Menéndez Pelayo en convenio con el Centro de Estudios Políticos y Constitucionales de España. Profesor de Derecho Constitucional de la Fundación Universitaria Juan de Castellanos de Tunja. Twitter: @FerTovarU
} 
SUMARIO. Introducción. 1. La teoría de la sustitución constitucional. 2. La teoría de la sustitución: ¿ejercicio hermenéutico o mutación constitucional?. 3. Análisis del juicio de sustitución. 4. La objeción democrática frente a la teoría de la sustitución y su respuesta. 4.1. La objeción democrática. 4.2. Una respuesta a la objeción democrática desde la teoría de la sustitución. Conclusiones. Bibliografía.

\section{Introducción}

Con la aparición de la teoría de la inconstitucionalidad por sustitución en la jurisprudencia de la Corte Constitucional colombiana, cuyo origen se remonta a la sentencia C-551 de 2003, surgió un nuevo matiz relacionado con el constructo doctrinario de los límites al poder de reforma en el contexto jurídico - político de este país. Dicho matiz, se concreta en la diferenciación de los conceptos de poder constituyente y poder de reforma: en primer lugar, el poder constituyente se trata de un poder político, creador, fuente de la elaboración de la norma constitucional, el cual es ajeno a la esfera del control jurisdiccional, es decir se trata de un poder ilimitado o absoluto (A. Negri, 1994 p. 18); y por otro lado el poder de reforma consiste en la facultad de modificar la Constitución, la cual es propia del órgano legislativo como principal representante del pueblo. Se trata de un poder constituido supeditado a los controles y límites establecidos en la norma superior, los cuales pueden ser materiales o formales ${ }^{2}$. Hasta aquí, bien se podría afirmar que no hay ningún nuevo aporte y que a grandes rasgos lo que hemos acotado ya ha sido decantado ampliamente por la teoría constitucional. Sin embargo, la distinción conceptual entre poder constituyente y poder de reforma se enmarca como una vital premisa respecto de lo que se entiende como sustitución constitucional.

Así las cosas, la sustitución constitucional consiste en el reemplazo de uno o varios elementos definitorios ${ }^{3}$ de la identidad y/o el concepto de Constitución, cuya invalidez subyace de la incompetencia del órgano de reforma para efectuar la eliminación de aquellos elementos. Este fenómeno se explica entendiendo que la facultad de reformar la Constitución no cobija la supresión de principios estructurales de ésta, sin los cuales la misma no sería reconocible, pues aquella facultad de sustituirla corresponde de manera exclusiva al constituyente originario.

Todo esto configura la interpretación que la Corte le ha dado al artículo 241,

\footnotetext{
2 Materiales cuando una Constitución establece disposiciones o partes que no pueden ser reformadas, como la italiana que prohíbe modificar la forma republicana de ese Estado; y son límites formales cuando la Constitución establece cuáles son los trámites y requisitos para su reforma.

${ }^{3}$ La Corte Constitucional colombiana no ha establecido un concepto unívoco acerca de lo que debe entenderse por "elementos definitorios de la Constitución"; sin embargo, podría señalarse que se trata de un conjunto de principios que reflejan los rasgos de identidad de la misma, es decir, se trata de elementos sin los cuales la Constitución no sería la misma o no podría entenderse como tal; por ejemplo cambiar la forma republicana del Estado colombiano por una monarquía, entraña una afectación a un elemento definitorio de la Carta, y más tratándose de un Estado que desde su origen siempre ha sido una república. No obstante, lo que sí ha señalado la Corte en varias sentencias es que corresponde al Juez constitucional determinar cuáles son esos elementos definitorios y ver si han sido reemplazados. Aunado a esto también se ha afirmado que la teoría de la sustitución es una doctrina en desarrollo, por lo cual ha de analizarse caso por caso, tal y como ha sido acotado en varias sentencias como la C-1040 de 2005, C-141 de 2010, C-574 de 2011, entre otras. Por último debe aclararse que la expresión "elementos definitorios" es sinónima de otras como principios estructurales, definitorios o axiales de la Constitución.
} 
numerales 1 y 2 de la Carta colombiana ${ }^{4}$ en la línea jurisprudencial iniciada con la sentencia C-551 de 2003, doctrina que ha tenido varios detractores, incluso al interior del Alto Tribunal. Quienes rechazan esta teoría, argumentan entre otras cosas que se trata de una interpretación errónea del artículo precitado, pues lo que en verdad se debe deducir es que la Corte está únicamente investida con la potestad de decidir sobre la validez de las reformas (y referendos reformatorios), tomando como base exclusivamente las cláusulas que establecen los procedimientos para el perfeccionamiento jurídico de las modificaciones constitucionales. Por esta razón, los contradictores de la teoría de inconstitucionalidad por sustitución han señalado que aquella doctrina va en contra vía de la Carta, como quiera que en la práctica la Corte termina efectuando un control material de constitucionalidad ${ }^{5}$, el cual nunca fue establecido por el constituyente, y se estaría soslayando el principio de legalidad, pues la Corte Constitucional es también un órgano constituido. Esta afirmación será analizada en el presente trabajo de tal forma que se logre establecer si el razonamiento jurídico efectuado por el Alto Tribunal ha sido apropiado o por el contrario nos encontramos frente a una posible mutación de la Constitución originada en la interpretación de la Corte.

Por otro lado, la teoría de la sustitución refleja una vez más el problema de la dificultad contra mayoritaria u objeción democrática al control de constitucionalidad, la cual se resume en el cuestionamiento a la revisión de leyes y/o reformas (emanadas de representantes elegidos por el pueblo), por parte de jueces constitucionales carentes de legitimidad popular. En ese sentido, es mi intención proponer una respuesta desde la doctrina mencionada a esta objeción, para así concretar una contestación satisfactoria desde el punto de vista democrático.

Así las cosas, se procederá en primera medida a matizar el concepto de sustitución constitucional para después contrastarlo con las nociones básicas de la teoría de la mutación, luego se abordarán los aspectos más relevantes del juicio o test de sustitución que la Corte ha implementado y finalmente se ha de plantear lo referente al tema de la objeción democrática que ha sido mencionado en el párrafo anterior.

\section{La teoría de la sustitución constitucional}

La sustitución de la Constitución es un fenómeno de connotación política y jurídica a la vez, es evidentemente política por cuanto quienes pudieren sustituir la Carta son los órganos políticos como el Congreso o una Asamblea Constituyente, o inclusive de manera indirecta el Gobierno Nacional cuando formula un proyecto de reforma constitucional; es decir, son los actores políticos quienes desde su esfera de intervención pueden participar en el fenómeno de sustitución de la Carta Política. Ahora, la connotación jurídica del fenómeno de sustitución constitucional subyace de

\footnotetext{
${ }^{4}$ El artículo 241 de la Constitución colombiana y sus numerales 1 y 2 señalan: "ARTICULO 241.A la Corte Constitucional se le confía la guarda de la integridad y supremacía de la Constitución, en los estrictos y precisos términos de este artículo. Con tal fin, cumplirá las siguientes funciones: 1. Decidir sobre las demandas de inconstitucionalidad que promuevan los ciudadanos contra los actos reformatorios de la Constitución, cualquiera que sea su origen, sólo por vicios de procedimiento en su formación.

2. Decidir, con anterioridad al pronunciamiento popular, sobre la constitucionalidad de la convocatoria a un referendo o a una Asamblea Constituyente para reformar la Constitución, sólo por vicios de procedimiento en su formación." (subrayado fuera de texto).

5 Esta postura se puede observar con claridad en los salvamentos de voto de los Magistrados Pinilla y Sierra formulados en la sentencia C-588 de 2009.
} 
dos factores: el primer factor se explica teniendo en cuenta que la sustitución ocurre como consecuencia de una reforma o un cambio constitucional de la Norma Fundamental del ordenamiento; y el segundo factor se explica partiendo de la idea que la sustitución no es per se inválida, siempre y cuando el órgano sustituidor posea la facultad de llevarla a cabo. Por ejemplo, una Asamblea Constituyente tiene la potestad de sustituir uno o varios elementos de una Constitución vigente, es más esta potestad (competencia) incluye la de cambiar totalmente la Carta por otra distinta. No así sucede cuando es un órgano de reforma el que sustituye la Norma Superior, como quiera que la facultad de reformar no trae implícita la de reemplazar, subvertir o eliminar elementos sobre los que se cimienta la identidad y/o el concepto de una Constitución.

Lo anterior, implica el desarrollo de un principio fundamental en todo ordenamiento jurídico como es el principio de legalidad, el cual establece que a los servidores públicos solo les es permitido hacer lo que señalan la Constitución y las leyes. En ese sentido, como se ha podido observar, básicamente la doctrina de la sustitución se fundamenta en el hecho de que los órganos de reforma no pueden so pretexto de enmendar la Carta sustituir o reemplazar elementos definitorios de la misma, ya que ello implicaría el desconocimiento del principio de legalidad, además de soslayar la propia identidad constitucional.

\section{La teoría de la sustitución: ¿ejercicio hermenéutico o mutación constitucional?}

El primer tratadista que se atrevió a escribir sobre la mutación constitucional fue Georg Jellinek a principios del siglo XX en su ensayo "Reforma y Mutación de la Constitución", en dicha obra el jurista alemán se empeñó en clasificar los tipos de mutación, partiendo de una definición elemental de este fenómeno, esto es concibiéndolo básicamente como una modificación no formal de las cláusulas constitucionales sin afectar su tenor literal (G.Jellinek, 1991).

Bajo esa lógica y a la luz del artículo 241 de la Constitución de Colombia (anteriormente citado), procederemos a analizar si con la inserción de la doctrina de inconstitucionalidad por sustitución mutó la disposición antes mencionada vía interpretación de la Corte Constitucional.

Ciertamente la cuestión recae sobre lo que se entiende respecto de la expresión "vicios de procedimiento en su formación"6. Así las cosas, podemos decir que cuando hablamos de vicios de procedimiento en la reforma constitucional, nos referimos a la inobservancia de las reglas que establecen el cauce que han de seguir los respectivos trámites para lograr el perfeccionamiento del acto jurídico, mediante el cual se efectúa la modificación de una o varias disposiciones constitucionales. Esta construcción conceptual, surge a partir de una noción de vicios del procedimiento legislativo, que en definitiva se aplica a la reforma; pues ésta a su vez se encuadra como un producto del legislador.

Desde el punto de vista de la ley, se admite una clasificación bipartita entre vicios formales y vicios materiales; no obstante no cabe aplicar el concepto de vicio material de la reforma en el ordenamiento colombiano, pues la Constitución no contempla la existencia de cláusulas de intangibilidad o inmodificables y además proscribe a la Corte Constitucional la potestad de realizar juicios materiales en el

\footnotetext{
${ }^{6}$ Es decir, vicios de procedimiento en la formación de las reformas constitucionales o de las leyes a través de las cuales se convocan referendos reformatorios
} 
examen de constitucionalidad de las reformas, reduciendo la competencia de este órgano a decidir única y exclusivamente la validez de las enmiendas en relación con los vicios de procedimiento en su formación.

Así las cosas, es procedente ahora determinar los alcances del concepto de vicios de procedimiento planteado en el artículo 241 superior, de tal modo que podamos aclarar si es posible equiparar el vicio de procedimiento al vicio de forma y al de competencia.

Al respecto la profesora Paloma Biglino Campos, relaciona dos clasificaciones de los vicios de la Ley formuladas por dos autores: la primera, propuesta por Alessandro Pizorusso, consiste en clasificar los vicios en materiales y formales, entendiendo que estos últimos suponen la inobservancia del procedimiento (P. Biglino, 1991, p. 101); la segunda clasificación la realiza Gustavo Zagrebelsky, en la cual distingue los vicios sustanciales, procedimentales y de competencia, entendiendo que la categoría procedimental abarca los vicios formales (P. Biglino, 1991, p. 101).

En el contexto de la Constitución de Colombia, debemos acudir a su tenor literal para así establecer el significado de vicios de procedimiento. En ese sentido, se observa que el artículo 241 de la Carta otorga la función de decidir sobre las demandas de inconstitucionalidad contra actos reformatorios, solo por "vicios de procedimiento en su formación", de igual modo concede al Juez Constitucional la facultad de decidir con anterioridad al pronunciamiento popular sobre la validez de las convocatorias al pueblo para adelantar un referendo constitucional o la aprobación de una asamblea constituyente, bajo el presupuesto de los vicios de procedimiento en la formación del acto.

De lo anterior, se infiere que, si bien el constituyente utilizó el término vicios de procedimiento, no los diferencia de los vicios formales. A esta conclusión llegamos luego de observar en conjunto el texto constitucional, ya que el artículo 242, numeral 3 señala que: "Las acciones por vicios de forma caducan en el término de un año, contado desde la publicación del respectivo acto." (subrayado fuera de texto).Bajo esta premisa sería inocuo afirmar que la Carta establezca un término de caducidad para vicios formales y no lo señale para los vicios de procedimiento; del mismo modo se observa que la expresión "vicios de forma" aparece una sola vez en la Constitución, sin que de ello derive una intención del constituyente de distinguir entre los dos enunciados; es decir, de acuerdo con la literalidad de la Norma Suprema colombiana, colegimos que se trata de sinónimos.

Sin embargo, hay sectores de la doctrina que sostienen que la forma se distingue del procedimiento como una categoría general que concentra todos los requisitos que no son de contenido, lo cual incluye presupuestos que no hacen parte del procedimiento en estricto sentido (P. Biglino, 1991, p. 103). Dicho en otras palabras, se puede decir que la forma es el género y el procedimiento la especie.

Ahora, en el entendido que la forma es una categoría general, cabría incluir dentro de la misma el presupuesto de la competencia (G. Zagrebelsky, 1988), como quiera que todo acto jurídico efectuado por una autoridad no competente, carece de validez. De modo que la observancia impecable por parte del órgano de reforma de los procedimientos señalados en la Constitución y la Ley, no lo exime de un juicio de competencia, en virtud de los principios de legalidad y supremacía de la integridad constitucional. De esta manera hemos de concluir que el ejercicio interpretativo realizado por la Corte no muta el contenido del artículo 241; sino que lo optimiza a través de un método sistemático, armonizándolo con los principios antes 
mencionados.

\section{Análisis del juicio de sustitución}

Para el análisis del juicio o test de sustitución, no nos vamos a detener en los casos concretos de cada uno de los fallos que componen la línea jurisprudencial; pero sí tendremos que abordar el desarrollo evolutivo que ha tenido este método.

Al principio, para soportar la ocurrencia de una sustitución constitucional, bastaba con señalar la supresión de un principio definitorio de la Constitución, el cual sería eventualmente reemplazado como consecuencia de la reforma y a su vez explicar los motivos por los cuales podría de deducirse el reemplazo de un principio de esta categoría (Sentencia C-551 de 2003). Luego, con las sentencias C- 970 y C971 de 2004, se avanzó hacia una estructura lógica del test de sustitución, donde en primer lugar se debe enunciar el elemento definitorio de la constitución que podría ser sustituido, posteriormente se ha de determinar los alcances de la reforma y finalmente se contrasta el principio definitorio con la misma, para así poder establecer si hay sustitución constitucional o no. De otro lado, el gran aporte a esta doctrina, es sin duda el juicio de sustitución legado en la sentencia C-1040 de 2005. En este fallo la Corte asumió una mayor carga argumentativa a la hora de motivar la existencia o no del fenómeno de sustitución. No se trataba únicamente de señalar un principio definitorio de la Carta con sus efectos, determinar los alcances de la norma respecto del principio definitorio y establecer si la reforma reemplazaba el principio definitorio. A partir de aquel fallo, además se tendría que hallar múltiples referentes normativos al principio definitorio, es decir que este último debe desarrollarse a lo largo del entramado constitucional; no en un solo artículo ya que la Carta colombiana no estableció la existencia de cláusulas pétreas o inamovibles. De otra parte, debe quedar absolutamente claro en el caso respectivo, que se observa cabalmente el reemplazo de un elemento definitorio de la Constitución y no una simple contrariedad, modificación o afectación de este. Por último, si el nuevo elemento definitorio no es armónicamente compatible con la Constitución, esto es, si aún con la nueva incorporación no se puede afirmar que la Carta sigue cobrando plena vigencia en relación con los demás aspectos que le dan identidad, se colige que el legislador ha sustituido la Norma Fundamental y por ende ha excedido su competencia que es la de reformar mas no sustituir la Constitución.

Un buen ejemplo de la aplicación de este test, lo encontramos en la sentencia C-588 de 2009, fallo en el cual se estudió la constitucionalidad del Acto legislativo 1 de 2008 que reformó el artículo $125^{7}$ de la Carta, norma que fija ciertas reglas sobre el acceso de la ciudadanía a empleos públicos, dentro de las cuales está el concurso de méritos como requisito previo a entrar a la carrera administrativa.

Con dicha reforma, se creó una disposición transitoria ${ }^{8}$ cuya finalidad era la

\footnotetext{
${ }^{7}$ El artículo 125 de la Constitución colombiana señala: "Los empleos en los órganos y entidades del Estado son de carrera. Se exceptúan los de elección popular, los de libre nombramiento y remoción, los de trabajadores oficiales y los demás que determine la ley.

Los funcionarios, cuyo sistema de nombramiento no haya sido determinado por la Constitución o la ley, serán nombrados por concurso público.

El ingreso a los cargos de carrera y el ascenso en los mismos, se harán previo cumplimiento de los requisitos y condiciones que fije la ley para determinar los méritos y calidades de los aspirantes. (...)" (Subraya fuera de texto)

${ }^{8}$ La disposición transitoria que dio paso a la carrera administrativa sin necesidad de concurso es la
} 
de inscribir de manera automática en la carrera administrativa a funcionarios que se encontraban nombrados en provisionalidad, sin necesidad de un concurso público durante un período de tres años. Al estudiar la reforma, la Corte encontró que dicha modificación implicaba una sustitución constitucional del principio democrático, pues se privaba a la ciudadanía de acceder a cargos públicos de manera transparente; es decir, que el acceso a la carrera administrativa también es desarrollo del principio democrático, el cual implica el derecho a elegir, ser elegido y desempeñar empleos públicos. Y no solo eso, sino que también desarrolla el principio de igualdad pues un concurso público como acceso a la carrera administrativa, presupone que haya igualdad ante la ley, igualdad de oportunidades e igualdad de condiciones.

En ese orden de ideas, se observan dos principios o elementos definitorios de la Constitución: igualdad y democracia, que son desarrollados a lo largo de la Constitución ${ }^{9}$ y sustituidos con ocasión de la reforma precitada; es decir no se trata de dos artículos o disposiciones aisladas, su afectación en el caso concreto implica la creación de una norma que no es armónicamente compatible con la Carta, pues es difícil sostener que una disposición como esta es más democrática y promueve condiciones de igualdad, cuando la regla anterior contenía mayores garantías en relación con estos principios.

Ahora volviendo al test de sustitución, la imposición de una carga en la argumentación está plenamente arraigada en la jurisprudencia de la Corte. A tal punto que se convirtió en un requisito fundamental el de alimentar con argumentos y razonamientos este test, tanto para demandantes que alegan vicios de competencia en las reformas a la Constitución; como para el Alto Tribunal en la fundamentación de sus propias sentencias.

El aumento de la carga argumentativa en la consolidación jurisprudencial de este test, deja entrever cierta intención de la Corte Constitucional de demostrar que no se trata de un juicio material frente a los cambios de la Constitución; pues el artículo 241 es categórico al señalar que la función de la Corte se circunscribe a pronunciarse exclusivamente con base en vicios de procedimiento. Esta última reflexión ha sido refrendada en las sentencias C-574 de 2011, C-249 de 2012, C288 de 2012, C-1056 de 2012 y C-579 de 2013, que podríamos decir continúan desarrollando la teoría de la sustitución constitucional. Pero además contemplan un paso adicional como es el de efectuar el denominado "test de efectividad de la reforma" que también ha sido traído a colación en la providencia C-588 de 2009 y mencionado por primera vez en la sentencia C-551 de 2003.

De acuerdo con el test de efectividad, se debe observar la norma antes y

siguiente:"PARÁGRAFO TRANSITORIO: Durante un tiempo de tres (3) años contados a partir de la vigencia del presente acto legislativo, la Comisión Nacional del Servicio Civil implementará los mecanismos necesarios para inscribir en carrera administrativa de manera extraordinaria y sin necesidad de concurso público a los servidores que a la fecha de publicación de la Ley 909 del 2004 estuviesen ocupando cargos de carrera vacantes de forma definitiva en calidad de provisionales o de encargados del sistema general de carrera siempre y cuando cumplieran las calidades y requisitos exigidos para su desempeño al momento de comenzar a ejercerlo y que a la fecha de la inscripción extraordinaria continúen desempeñando dichos cargos de carrera. Igual derecho y en las mismas condiciones tendrán los servidores de los sistemas especiales y específicos de la carrera, para lo cual la entidad competente, dentro del mismo término adelantará los trámites respectivos de inscripción. (...)"

${ }^{9}$ Por ejemplo, el principio democrático tiene múltiples referentes normativos en la Constitución como son: el artículo 3 el cual señala que la soberanía reside exclusivamente en el pueblo; el artículo 40 que establece los derechos de los ciudadanos, entre ellos el de elegir, ser elegido y ocupar cargos públicos; el título IV contiene reglas sobre la participación democrática y los partidos políticos, entre otras tantas disposiciones que dan cuenta del desarrollo constitucional de este principio. 
después de la reforma. Si su contenido sigue siendo el mismo, no se trata de una reforma; sino de una "decisión política particular"10. Esta nueva etapa del juicio de sustitución por así llamarla entraña tres criterios esenciales: el primer criterio como ya lo habíamos señalado consiste en verificar si la disposiciones modificadas son idénticas a las disposiciones constitucionales antes de la reforma, de manera que si las normas son idénticas, no se trataría de una reforma sino de una (valga la redundancia) decisión política particular; el segundo criterio implica la prohibición de reformas ad hoc destinadas a una sola persona, o a un grupo específico de personas soslayando el principio de generalidad de las normas; y finalmente el último criterio señala la prohibición de reformas tácitas, esto es que se sustituyan principios estructurales de la Constitución frente a los cuales no iba dirigida la reforma (G. Ramírez y P. Robledo, 2013, p. 595).

Además de lo anterior, se incorporan nuevos criterios que podríamos decir respetan la pervivencia de la línea jurisprudencial; ${ }^{11} \sin$ embargo, tienden a modularla o racionalizarla con la finalidad que no se desdibuje el papel de la Corte en cuanto a sus potestades y la propia función de fungir como el supremo intérprete de la Constitución.

El primero de los criterios es la cualificación de la acción pública de inconstitucionalidad, el cual se refiere a la carga argumentativa que ha de asumir el accionante cuando formula los cargos de sustitución, pues no cualquier reforma implica que se esté sustituyendo la Constitución. El segundo criterio consiste en la precisión conceptual, la cual implica hacer claridad en que no se trata de un juicio material de la reforma, es decir que no se toma como parámetro de inconstitucionalidad de la enmienda cualquier disposición constitucional, debe ser un principio definitorio el que es reemplazado o subvertido. Por último, el tercer criterio establece la sujeción metodológica del juicio de sustitución; esto debe entenderse como un límite que se impone la Corte a sí misma, en aras de no caer en una discrecionalidad excesiva, es decir que el Tribunal Constitucional, así como exige a los accionantes suficiencia en los argumentos en las demandas de inconstitucionalidad, debe asumir su propia carga interpretativa y argumentativa siguiendo estrictamente el precedente jurisprudencial, mucho más teniendo en cuenta el desarrollo evolutivo que ha tenido el test de sustitución (G. Ramírez y P. Robledo, 2013, p. 597).

Para concluir este punto, merece la pena destacar la evolución jurisprudencial del test de sustitución y la incorporación de nuevos elementos que en general enriquecen esta doctrina. No obstante, hemos de tomar distancia respecto del test de efectividad de la reformar, por cuanto a nuestro juicio más que tratarse de un control material implícito originado en el estudio de los vicios de competencia; consiste en un control material evidente, pues ello entraña el comparar las disposiciones constitucionales antes y después de una reforma buscando que no haya identidad entre ellas, en definitiva este no puede ser un parámetro de validez, mucho menos cuando se cuenta con herramientas muy razonables en las distintas etapas del juicio de sustitución. Si bien podemos señalar que existe una pretensión de generalidad y abstracción de las normas constitucionales, esto no es un principio

\footnotetext{
${ }^{10}$ Esta expresión resulta algo problemática si tenemos en cuenta que el control de constitucionalidad se ejerce respecto de normas jurídicas y no sobre decisiones políticas. Como quiera que se trata de una potestad otorgada en los estrictos términos señalados en la Constitución, la Corte carece de facultades para enjuiciar decisiones políticas.

11 Tal y como se puede verificar en la sentencia C-288 de 2012, en la cual se estudió una demanda de inconstitucionalidad contra el Acto Legislativo 03 de 2001, a través del cual se incorporó el principio de sostenibilidad fiscal en la Constitución.
} 
absoluto ni tampoco un elemento definitorio de la identidad de la Constitución. Además, resulta contradictorio que la Corte emplee criterios para evitar caer en juicios materiales frente a los cambios constitucionales y por otro lado emplee un test que consiste en verificar la literalidad del texto constitucional antes y después de una reforma. Se trata entonces de un juicio material evidente, pues su razón de ser más que verificar un exceso en la competencia del legislativo; se convierte en analizar en forma directa el contenido de una norma constitucional antes y después de su modificación, y en caso de que sus efectos sean los mismos, dice la Corte no es una reforma.

\section{La objeción democrática frente a la teoría de la sustitución y su respuesta}

En la teoría constitucional contemporánea, hay un tema que siempre ha estado en boga y este es el de la objeción democrática al control de constitucionalidad que ejercen los jueces respecto de las leyes. La propuesta del control de constitucionalidad se encuentra plenamente arraigada en el ordenamiento colombiano, incluso desde antes que Kelsen publicara su obra "La Garantía Jurisdiccional de la Constitución. La justicia constitucional" en 1928, pues con la reforma de $1910^{12}$, se introdujo en la Carta la acción pública de inconstitucionalidad, es decir la posibilidad de que los ciudadanos pudieran impugnar ante la Corte Suprema de Justicia, la validez de las leyes por su contradicción con la Constitución. En la actualidad hay sectores de la doctrina que se oponen al control de constitucionalidad ejercido por los jueces, por considerarlo una institución antidemocrática, considerando la legitimidad con la que cuenta el legislativo al ser un órgano directamente elegido por el pueblo. Esta crítica crece sobre todo si hablamos del control al poder de reforma, el cual ha sido reprochado incluso por autores afines al control de constitucionalidad. ${ }^{13}$

En este acápite vamos a señalar con claridad los principales argumentos en contra del control de constitucionalidad, y fijaremos un posicionamiento respecto de esta tensión buscando siempre hacerlo de la manera más objetiva posible, además teniendo en cuenta la construcción conceptual y normativa de la teoría de la sustitución constitucional.

\subsection{La objeción democrática}

Jeremy Waldron es quizá el teórico más reconocido que arremete en contra del control de constitucionalidad de las leyes (también de las reformas). Su argumento fundamental se basa en la deficiencia de legitimidad democrática para restringir al órgano legislativo, que sí cuenta con ella. Para Waldron, propugnar a favor de la supremacía interpretativa de la Corte Suprema de Justicia, señalando las deficiencia propias de la democracia, equivale a legitimar a la monarquía o a la Cámara Alta del Reino Unido. Teniendo en cuenta las imperfecciones de la Cámara Baja, de acuerdo con este autor lo correcto sería revisar, corregir y mejorar el proceso democrático en vez de privilegiar un procedimiento aristocrático (D. Peña,

\footnotetext{
12 Me refiero al Acto Legislativo 3 de 1910, reforma que dio origen al control de constitucionalidad concentrado en el ordenamiento jurídico colombiano.

${ }^{13}$ Por ejemplo, Jorge Carpizo rechazaba la idea que un Tribunal Constitucional ejerciera un control de constitucionalidad respecto de las reformas; como excepción a esta regla planteaba la validez de esté control siempre y cuando aquella potestad estuviera expresa y clara en la Constitución, tanto por vicios materiales como de procedimiento, estrictamente en los términos señalados en ella. Cfr. J. Carpizo, "El Tribunal Constitucional y el control de la reforma constitucional", Revista Boletín Mexicano de derecho comparado, num. 125, UNAM, México D.F., 2009, pp. 785 - 794.
} 
2013, p. 227) como se pensaría que es el control judicial de constitucionalidad. Este autor otorga un valor superior al legislador por su legitimidad democrática, en otras palabras, asume que la única valoración legítima jurídica subyace de las mayorías parlamentarias, que por la misma razón poseen libertad de configuración legislativa, la cual se sustenta en la forma de elección de sus miembros y en los procesos deliberativos tendientes a solucionar los desacuerdos existentes en la sociedad plural que representan (D. Higuera, 2011, pp. 261 y 262). De igual modo considera que no es justificado que un órgano que no es elegido popularmente resuelva asuntos que pueden ser decididos en sede política, cuestiona por ejemplo el hecho que los jueces, también toman sus decisiones de acuerdo a la regla de la mayoría, en ese sentido no podría justificarse aquel argumento (R. Gargarella y J.L. Martí, 2005 , p. 28), Waldron privilegia el razonamiento en sede parlamentaria por ser más abierta y franca, de lo que podría ser en sede judicial (R. Gargarella y J.L. Martí, 2005, p. 30).

De otra parte, según Victor Ferreres existen tres circunstancias que provocan la aparición de una objeción democrática al control de constitucionalidad, que podríamos aludir en los siguientes términos: 1) la poca legitimidad democrática de origen del juez constitucional; 2) la rigidez constitucional y 3) la existencia de controversias en la interpretación de la Constitución (V. Ferreres, 2012, p. 43). La primera circunstancia hace referencia a la manera en la que son elegidos los jueces constitucionales, por ejemplo hay ordenamientos en los cuales son elegidos por el parlamento para periodos específicamente señalados(V. Ferreres, 2012, p. 44),así las cosas, se puede afirmar que gozan de mayor legitimidad que en otros sistemas, por ejemplo donde pudieren ser elegidos por los mismos tribunales; ${ }^{14}$ la segunda circunstancia, hace referencia a ordenamientos donde la revisión constitucional es compleja y en muchas ocasiones políticamente inviable dificultando al hacedor de leyes efectuar una respuesta frente a declaración de invalidez de la norma aprobada; ${ }^{15}$ finalmente la tercera circunstancia, sobre aspectos controversiales en la interpretación de la Constitución, dan cuenta de los casos difíciles, donde es poco probable que haya consenso en los tribunales constitucionales, viéndose compelidos a acudir a la regla de la mayoría, y de este modo el argumento objeción democrática toma aún más fuerza; pensemos en casos como el aborto, la eutanasia, el matrimonio entre personas del mismo sexo, aquí la cuestión (con tintes retóricos si se quiere) que surge es si la solución de esa clase de controversias conviene atribuirlas al parlamento o a los jueces (J. Waldron, 2005, pp. 274 y 275).

Ahora, si llevamos la objeción democrática al ámbito de la teoría de los vicios competenciales (sustitución constitucional), su argumento toma una gran relevancia, especialmente si nos hacemos los siguientes planteamientos: 1) ¿Cómo puede ser legítimo que un Tribunal conformado por nueve magistrados (no elegidos democráticamente) determine los límites competenciales del órgano legislativo en relación con la revisión de la Constitución?; y 2) suponiendo que la teoría de la sustitución constitucional es ampliamente aceptada por el pueblo, como quiera que este es el creador de la Constitución, sería el encargado de establecer los elementos esenciales de la Constitución; así las cosas, si el pueblo aprueba directamente o por medio de sus representantes una reforma constitucional, es porque considera que la materia enmendada no representa un elemento definitorio de la Constitución (C. Bernal, 2011). ${ }^{16}$ Contestaremos estos planteamientos en el

\footnotetext{
14 En Colombia antes de la Constitución de 1991, la Corte Suprema de Justicia, ejercía funciones de juez constitucional, sus integrantes eran elegidos por la misma corporación, de manera que en el contexto de la idea expuesta, tenían un mayor déficit de legitimidad democrática.

15 Naturalmente aquella respuesta sería una reforma constitucional.

16 Este planteamiento fue realizado por el profesor Carlos Bernal Pulido en la ponencia titulada
} 
siguiente punto en el cual procederemos a dar una respuesta a la objeción democrática como argumento contrario a la teoría de la sustitución constitucional.

\subsection{Una respuesta a la objeción democrática desde la teoría de la sustitución}

La objeción democrática desde su perspectiva más radical, tiene un serio problema y es el de caracterizar al órgano legislativo como una institución infalible por el hecho de su legitimidad democrática. Consideramos que esta objeción puede ser más o menos aceptada, dependiendo del contexto jurídico en el que se desarrolla. Por ejemplo, en Estados donde el control de constitucionalidad difuso está instituido, puede resultar más razonable verter argumentos en contra de este, teniendo en cuenta que cualquier juez puede inaplicar normas legales en caso de encontrarlas incompatibles con la Constitución, lo cual en cierto modo desconoce la dignidad democrática del legislador; es decir no causa el mismo impacto que una norma sea inaplicada por un Juez Municipal, que por la Corte Suprema de Justicia. Por otro lado, De Vega ha señalado que el Estado Constitucional se apoya en dos pilares fundamentales, como son el principio democrático y el de Supremacía de la Constitución (P. De Vega, 1985, p.15) y es que la función principal de la Constitución es limitar el ejercicio del poder político (R. Guastini, 1999, pp. 169 y $170)$, de manera que si se rechaza radicalmente el control de constitucionalidad, se ataca indirectamente el concepto de Constitución, con todo lo que ello conlleva (derechos fundamentales, garantías democráticas, separación de poderes y hasta el Estado de Derecho).

Waldron soslaya el hecho de que los parlamentos son instituciones que obedecen a intereses políticos que pueden ser o no altruistas; pero en todo caso conformados por partidos políticos con identidades ideológicas que persiguen objetivos comunes. Un parlamento sin límites constitucionales reales puede fácilmente establecer una dictadura, legitimar la violación de los derechos humanos y hasta desconocer las mínimas garantías democráticas, por ejemplo para que haya una oposición al gobierno de turno o para que haya alternancia en el acceso al poder. Por supuesto que hay que revisar las instituciones democráticas, corregirlas y mejorarlas; pero ¿mientras tanto qué? Sin duda, no hay un mejor mecanismo para garantizar los derechos constitucionalmente establecidos, que el control de constitucionalidad tanto difuso como concentrado.

Aun cuando pareciera que los conceptos de Constitución y democracia son incompatibles, es posible armonizarlos en el Estado Constitucional, es decir con la puesta en marcha de la democracia constitucional, que desde una perspectiva elemental significa el reconocimiento del carácter normativo de la Constitución, la cual se legitima en el establecimiento de un orden democrático. La democracia constitucional es una garantía de la efectividad de los derechos y libertades fundamentales gracias a su protección jurídica, que por supuesto viene incluida en el control de constitucionalidad. Asimismo, Bovero defiende esta idea al señalar que una democracia completamente inconstitucional, es susceptible de convertirse en una mayoría tiránica, usurpadora (M. Bovero, 2006, pp. 35 - 41) y desde luego según nuestro punto de vista, también incontenible.

Ahora, contestar a la objeción democrática afirmando que es legítimo el control de constitucionalidad de las leyes y los actos de revisión, por cuanto así lo

"Fundamentación y significado de la doctrina de la sustitución constitucional. Un análisis del control de constitucionalidad de las reformas a la Constitución en Colombia", presentada en el VII Encuentro de la Jurisdicción Constitucional: Diálogos con el mundo, realizado en octubre de 2011 en la ciudad de Bogotá, Colombia. 
establece la Constitución, y esta a su vez por su carácter normativo, vincula a todas las instituciones del Estado, sería una premisa tautológica y en últimas no justifica que un selecto grupo de juristas organizados en un tribunal, declaren la invalidez de leyes aprobadas por legisladores votados por millones de personas. Sin embargo, Alexy propone una salida interesante frente a esta objeción a la cual merece la pena adherirse (al menos los defensores del control judicial de constitucionalidad). El autor parte del supuesto que todos los poderes estatales emanan del pueblo. Por ende, esta premisa exige que tanto el parlamento como el Tribunal Constitucional, sean considerados representantes de este. El parlamento ha de representar políticamente a los ciudadanos, y el Tribunal Constitucional ejerce la representación argumentativa del pueblo; así, frente a los excesos del legislativo, el Tribunal no actúa contra el pueblo; sino en nombre del pueblo (R. Alexy, 2004, pp. 75 y 76).

En ese orden de ideas, nos permitimos formular la respuesta a los planteamientos realizados en el numeral anterior: frente a la cuestión de legitimidad de la Corte Constitucional para fijar límites competenciales al poder de reforma, diríamos que esta tiene su origen en la representación argumentativa que ejerce la Corte, en el entendido que todos los poderes estatales emanan del pueblo y a su vez se justifica en la intención de conjurar el ejercicio arbitrario de las mayorías legislativas, que de actuar sin control, podría subvertir el Estado constitucional, esta misma respuesta aplica para la determinación de elementos definitorios de la Constitución por parte del Alto Tribunal, que con base en su representación establece dichos elementos; más allá de la crítica metodológica que se pueda realizar, lo cual forma parte de otro debate.

Para finalizar este punto, es fundamental entender que la legitimidad democrática y la legitimidad judicial representan argumentos que se encuentran en tensión constante. Si la legitimidad democrática se sustenta en la elección popular de representantes, la judicial se cimienta en la producción de decisiones razonablemente fundamentadas. Así, la actuación del parlamento es controlada en sede constitucional, frente a excesos y omisiones; y de igual modo la producción de decisiones arbitrarias con fundamentos deficientes, es susceptible de ser limitada por el legislativo a través modificaciones constitucionales, o incluso por el pueblo a través de la activación del poder constituyente rompiendo con la norma primigenia. Es más, la emisión de sentencias jurídicamente bien fundamentadas que lleguen a ser insatisfactorias en un alto grado también pueden llegar a ser causa de una ruptura constitucional y la instauración de un nuevo ordenamiento (obviamente se trataría de un caso extremo). Y es que finalmente si se va a terminar sustituyendo la Constitución, ¿por qué no dejar que sea el constituyente originario el que establezca nuevos elementos definitorios de una Carta o excluya los mismos de la anterior?, ¿acaso no es esto más democrático que permitir que el legislativo suprima garantías esenciales y características de un ordenamiento bajo la bandera de la democracia de mayorías?

\section{Conclusiones}

El control de constitucionalidad ejercido bajo la doctrina de la sustitución constitucional, implica un juicio procedimental respecto de los actos reformatorios, toda vez que el factor competencia se convierte en un presupuesto de validez y además los enjuiciamientos materiales de las modificaciones constitucionales están proscritos.

El control de constitucionalidad por vicios de competencia, es decir la inconstitucionalidad por sustitución conlleva un control material implícito que se 
soporta en la metodología que se debe llevar a cabo para concluir que el órgano de reforma ha excedido su competencia.

La Corte Constitucional en ejercicio de sus funciones no ha mutado el tenor literal del artículo 241 superior, sino que ha efectuado un ejercicio de interpretación textual y sistemática, ya que optimiza los principios de legalidad y supremacía constitucional al diferenciar las potestades de reformar y sustituir la Constitución.

La Corte Constitucional como órgano constituido ejerce la guarda de la Constitución por mandato del constituyente, en ese sentido funge como representante argumentativo del pueblo y como tal limita los excesos del legislador dentro de los cuales está el de sustituir la Constitución.

La exigencia argumentativa que asume la Corte y a su vez impone a los eventuales accionantes contesta a la objeción democrática en términos de razonabilidad, pues no frente a cualquier argumento la Corte va a invalidar una reforma por vicios de sustitución. Desde esa perspectiva es deferente con el órgano de reforma; y más teniendo en cuenta que en sede política más allá de fijarse en los argumentos, lo que vale son los votos en uno u otro sentido, lo cual dista del control de constitucionalidad donde a pesar de que también se aplica la regla de la mayoría, la construcción argumentativa de las sentencias es el principal aspecto legitimador de dicho control.

La teoría de la sustitución representa una postura democrática al establecer que las alteraciones de elementos axiales de la Constitución deban ser decididas por el constituyente originario (el pueblo) y no por el legislador, a quien corresponde ejercer el poder constituido de reforma.

La evolución jurisprudencial ha permitido la incorporación de nuevos elementos que han enriquecido el test de sustitución y a su vez han propendido por modularlo o racionalizarlo. Sin embargo, figuras como el test de efectividad o eficacia de la reforma podrían terminar desdibujando el papel de la Corte como quiera que llevado a la práctica implica el desarrollo de un juicio material explícito de los actos reformatorios de la Constitución, el cual no ha sido autorizado por el constituyente.

\section{Bibliografía}

ALEXY, R. (2004), "Derechos fundamentales y derechos humanos." En: El Derecho Contemporáneo. Lecciones Fundamentales para su estudio, Pachuca, Universidad Autónoma del Estado de Hidalgo, pp. 59 - 76.

BERNAL PULIDO, C. (2011), "Fundamentación y significado de la doctrina de la sustitución constitucional. Un análisis del control de constitucionalidad de las reformas a la Constitución en Colombia". En: HENAO PEREZ, J.C. (Ed.).Diálogos constitucionales de Colombia con el Mundo - VII Encuentro de la Jurisdicción Constitucional, Bogotá, Universidad Externado de Colombia, pp. 400 - 426.

BIGLINO CAMPOS, P. (1991), Los vicios en el procedimiento legislativo, Madrid, Centro de Estudios Constitucionales.

BOVERO, M. (2006), "Prefacio." En: SALAZAR UGARTE, Pedro, La democracia constitucional. Una radiografía teórica, México D.F., Fondo de Cultura Económica - 
Universidad Nacional Autónoma de México.

CARPIZO MCGREGOR, J. (2009), "El Tribunal Constitucional y el control de la reforma constitucional", Boletín Mexicano de Derecho Comparado, num. 125, pp. $735-794,2009$.

DE VEGA, P. (1985), La reforma constitucional y la problemática del poder constituyente, Madrid, Tecnos.

FERRERES COMELLA, V. (2007), Justicia constitucional y democracia, Madrid, Centro de Estudios Políticos y Constitucionales.

GARGARELLA, R, y MARTí, J.L. (2005), “Estudio Preliminar." En: WALDRON, Jeremy, Derecho y desacuerdos, Madrid, Marcial Pons, pp. 13 - 48.

GUASTINI, R. (2014), Interpretar y argumentar, Madrid, Centro de Estudios Políticos y Constitucionales.

GUASTINI, R. (1999), "Sobre el Concepto de Constitución", Cuestiones constitucionales, num.1, pp.161 - 176.

HIGUERA JIMÉNEZ, D. (2011), "El gobierno de los jueces, el control de constitucionalidad, entre la política, la democracia y el derecho", Principia luris, num. 16 , pp. $203-249$.

JELLINEK, G. (1991), Reforma y Mutación de la Constitución, Madrid, Centro de Estudios Constitucionales.

KELSEN, H. (2001), La Garantía Jurisdiccional de la Constitución (La Justicia Constitucional), México D.F., Instituto de Investigaciones Jurídicas - Universidad Nacional Autónoma de México.

NEGRI, A. (1994), El poder constituyente. Ensayo sobre las alternativas de la modernidad, Madrid, Librerías Prodhufi.

PEÑA RANGEL, D. (2013), "Constitucionalismo Popular Contestatario", Isonomía, num. 38 , pp. $225-243$.

RAMÍREZ CLEVES, G. y ROBLEDO SILVA, P. (2014), "La jurisprudencia constitucional colombiana en el año 2013: El control por sustitución y el amparo reforzado a los sujetos de especial protección constitucional", Anuario Iberoamericano de Justicia Constitucional, num. 18, Madrid, Centro de Estudios Políticos y Constitucionales, pp. $587-620$.

SALAZAR UGARTE, P. (2006), La democracia constitucional. Una radiografía teórica, México D.F., Fondo de Cultura Económica - Universidad Autónoma de México.

WALDRON, J. (2005), Derecho y desacuerdos, Madrid, Marcial Pons.

ZAGREBELSKY, G. (1988), La giustizia costituzionale, Bolonia, II Mulino.

\section{Jurisprudencia}

COLOMBIA, CORTE CONSTITUCIONAL, Sentencia C-551 de 2003, Magistrado 
Ponente EDUARDO MONTEALEGRE LYNETT.

COLOMBIA, CORTE CONSTITUCIONAL, Sentencia C-1200 de 2003, Magistrados Ponentes, MANUEL JOSÉ CEPEDA y RODRIGO ESCOBAR GIL.

COLOMBIA, CORTE CONSTITUCIONAL, Sentencia C-970 de 2004, Magistrado Ponente, RODRIGO ESCOBAR GIL.

COLOMBIA, CORTE CONSTITUCIONAL, Sentencia C-971 de 2004, Magistrado Ponente, MANUEL JOSÉ CEPEDA.

COLOMBIA, CORTE CONSTITUCIONAL, Sentencia C-1040 de 2005, Magistrados Ponentes, MANUEL JOSÉ CEPEDA, RODRIGO ESCOBAR GIL, MARCO GERARDO MONROY CABRA, HUMBERTO ANTONIO SIERRA PORTO, ÁLVARO TAFUR GALVIS, y CLARA INÉS VARGAS.

COLOMBIA, CORTE CONSTITUCIONAL, Sentencia C-588 de 2009, Magistrado Ponente, GABRIEL EDUARDO MENDOZA MARTELO.

COLOMBIA, CORTE CONSTITUCIONAL, Sentencia C-141 de 2010, Magistrado Ponente, HUMBERTO ANTONIO SIERRA PORTO.

COLOMBIA, CORTE CONSTITUCIONAL, Sentencia C-574 de 2011, Magistrado Ponente, JUAN CARLOS HENAO PÉREZ.

COLOMBIA, CORTE CONSTITUCIONAL, Sentencia C-249 de 2012, Magistrado Ponente, JUAN CARLOS HENAO PÉREZ.

COLOMBIA, CORTE CONSTITUCIONAL, Sentencia C-288 de 2012, Magistrado Ponente, LUIS ERNESTO VARGAS SILVA.

COLOMBIA, CORTE CONSTITUCIONAL, Sentencia C-1056 de 2012, Magistrado Ponente, NILSON PINILLA PINILLA.

COLOMBIA, CORTE CONSTITUCIONAL, Sentencia C-579 de 2013, Magistrado Ponente, JORGE IGNACIO PRETELT CHALJUB. 